\title{
Evaluation of satisfaction levels of expatriate patients presenting to emergency department
}

\author{
Süleyman Ersoy, ${ }^{1}$ Naime Meriç Konar, ${ }^{2}$ Hacı Mehmet Çalışkan, ${ }^{1}$ Bedriye Müge Sönmez, ${ }^{3}$ \\ Burak Çelik ${ }^{4}$
}

${ }^{1}$ Department of Emergency Medicine, ${ }^{2}$ Department of Medical Statistics, Kırşehir Ahi Evran University

Faculty of Medicine, Kırşehir; ${ }^{3}$ Department of Emergency Medicine, Dışkapı Yıldırım Beyazıt Training and

Research Hospital, Ankara; ${ }^{4}$ Department of Emergency Medicine, Kırşehir Training and Research Hospital, Kırşehir, Turkey

\begin{abstract}
People who emigrated from Turkey to European countries for work are called expatriate. It was aimed to analyze demographic characteristics of expatriate patients who presented to the emergency department, to compare satisfaction levels of emergency departments between their country of residence and Turkey, and to identify the factors that affect patient satisfaction. This descriptive study was conducted with questionnaires filled by face-to-face interviews in 150 expatriate patients who were living abroad, came to Turkey for vacation/annual permit and applied to the emergency
\end{abstract}

Correspondence: Süleyman Ersoy, Department of Emergency Medicine, Kırşehir Ahi Evran University Faculty of Medicine, Kırşehir, Turkey.

Tel.: +905064250516

E-mail: ersoydr@hotmail.com

Key words: Emergency department; expatriate; patient satisfaction; questionnaire.

Contributions: Conception: SE, HMC, BC; Methods: SE, NMK; Data Collection: SE, HMC, BC; Analyses: NMK, BMS; Writer: SE, NMK; Critical Review: BMS

Conflict of interest: The authors declare no conflict of interest.

Availability of data and materials: All data generated or analyzed during this study are included in this published article.

Ethics approval and consent to participate: An ethics approval was obtained for this study from the ethics committee of Ahi Evran University Faculty of Medicine (Approval numbered 2019-13/140 and approval date 16.07.2019). Informed consent obtained from the patients involved.

Informed consent: Written informed consent was obtained from a legally authorized representative(s) for anonymized patient information to be published in this article.

Received for publication: 16 April 2021.

Revision received: 16 July 2021.

Accepted for publication: 6 August 2021.

This work is licensed under a Creative Commons Attribution 4.0 License (by-nc 4.0).

(C) Copyright: the Author(s), 2021

Licensee PAGEPress, Italy

Emergency Care Journal 2021; 17:9812

doi:10.4081/ecj.2021.9812 department with any complaint. We found a statistically significant difference when we evaluated expatriate patients' monthly average number of emergency department applies and their views on priority to apply to emergency departments for health problems, the cleanliness of emergency departments, attitude of doctors, security and receptionist/nursing staff towards patients in Turkey and in their country of residence. It has been found that expatriates prefer the emergency department more in our country and they are more satisfied in their country of residence in terms of the cleanliness of emergency department, attitude of doctors, security and receptionist/nursing staff.

\section{Introduction}

Although satisfaction is a subjective perception of patient and patient relatives, patient satisfaction is frequently evaluated as an indicator of the quality of service provided in healthcare centers. Patient satisfaction is generally based on whether the service provided meets the expectations of the patient or the patient's perception of the service provided. ${ }^{1}$ Despite the fact that there are many factors that affect patient satisfaction, they can be grouped under three main titles as institutional characteristics, patients and service providers. ${ }^{2}$ Satisfaction is a complex concept associated with many factors including lifestyle, past experiences, expectations from the future, individual and social values. Patient satisfaction, which is associated with the perception of care outcomes and meeting expectations, can be defined differently by different people and even by the same people at different times. ${ }^{1}$

Emergency departments are units designed to meet the needs of patients in life-threatening situations and provide the necessary services, and they are open showcases of hospitals because they serve 24 hours a day. In recent years, concept of patient satisfaction is gaining importance in the literature related with emergency service. Since the beginning of 1960 people who migrated from Turkey to European countries, especially Germany, to work are called expatriates. Today expatriates, whose number is expressed in millions, often come to Turkey once a year, especially in summer, for holiday. ${ }^{3}$ In this period, expatriate patients are frequently encountered in emergency departments. In the literature, even though there are many studies about patient satisfaction in emergency departments, there is no study that compares the emergency department satisfaction of expatriate citizens in their country of residence and our country. The aim of this study is to research demographic characteristics of expatriate patients who presented to the emergency department, to compare satisfaction levels of emergency departments between their country of residence and Turkey, and to identify the factors that affect patient satisfaction. 


\section{Materials and Methods}

This was a descriptive study. This study was conducted in Kırşehir Training and Research Hospital Emergency Medicine Clinic after obtaining Ahi Evran University Faculty of Medicine Ethics Committee approval numbered 2019-13/140 and approval date 16.07.2019. In a previous study satisfaction rate of patients presenting to emergency service was $94.5 \% .{ }^{4}$ Considering this rate, the sample size required to determine $\mathrm{p}$ within the absolute percentage score of $\mathrm{d}$ with $90 \%$ confidence according to recommendation of WHO was determined as 143 for calculation of required sample size with 0.03 error and $90 \%$ confidence interval. ${ }^{5}$ Considering the data losses that may occur during the research, a larger sample (150) was created than recommended. For the sample selection method of the research, the individuals who came to the emergency room were selected by random method, which is one of the improbable sampling methods. 150 expatriate patients who were living abroad, came to Turkey for vacation/annual permit, over 18 years old, volunteered to participate in the study and applied to the emergency department with any complaint between the dates of 15 July 2019 and 30 October 2019 were included in the study. All participants can speak both Turkish and the language of the country they live in. Patients with poor consciousness, inability to communicate, in need of urgent intervention and without informed consent were excluded from the study. Our hospital is the only hospital in the city center and serves as a tertiary emergency department. The data were collected through face-to-face interviews using questionnaires prepared by the researcher. There are 33 questions in the questionnaire form, 7 of which are for the determination of demographic and clinical data, and 26 of them are for the perception of the services provided in the emergency department. Patients were asked for age, gender, educational status, the country of residence, whether they reside in a rural or urban area, the type of application to the emergency department and the complaint of applying to the emergency department in the first 7 questions.

\section{Statistical Analysis}

Normality assumption of numerical data was tested via Kolmogorov-Smirnov Test. Non-normally distributed continuous data were described as the median [Inter Quartile Range (IQR) 25$75 \%$. Continuous data with non-normal distribution were compared with Wilcoxon test, while categorical data were compared with McNemar test or Marginal Homogeneity test. Two-dimensional graphics were used to better understand the relationship between sociodemographic characteristics of expatriates and their views on emergency departments in Turkey and in their country of residence. All of the analyzes were performed with SPSS v.21.0 (IBM Corp. Released 2012. IBM SPSS Statistics for Windows, Version 21.0. Armonk, NY: IBM Corp.), $\mathrm{p}<0.05$ was considered statistically significant in all analyzes.

\section{Results}

Median (IQR 25-75\%) of age values of the participants were 38 [(18), 27 (25\%)- $45(75 \%)]$ respectively. When the sociodemographic data of the participants were examined $57.3 \%$ of the participants were male, $46.7 \%$ were high-school graduates, $49.3 \%$ were living in Germany and $81.3 \%$ were living in urban areas. On the other hand, $49.3 \%$ of the participants applied to the emergency department on foot and the most common complaints were flu (n:
14, 9.3\%), headache (n: $12,8 \%$ ) and fever (n: 10, 6.7\%), respectively (top 5 complaints with the highest frequency were reported, Table 1).

Expatriate patients' monthly median and IQR number of applications to the emergency department was calculated as 1 [(1), 1 $(25 \%)-2(75 \%)]$ in Turkey; while the monthly median and IQR number of applications to the emergency department was found as $1[(0), 1(25 \%)-1(75 \%)]$ in their country of residence $(\mathrm{p}<0.001)$. The rate of expatriates that state they apply to emergency department in Turkey just for emergencies was 4\% (n: 6), while $14.7 \%$ (n: 22) stated that they apply to emergency departments in their country of residence just for emergencies.

When the reasons for choosing our hospital's emergency department were examined, the most common reasons were the quick service in the emergency department (n: 68, 26\%), trust the emergency staff (n: 48, 18.4\%) and satisfaction with previous services (n: 44, 16.8\%; Figure 1). When views on preference of emergency departments in case of a health problem in country of residence and in Turkey were examined, $81.3 \%$ of the participants stated that they would firstly apply to emergency department in Turkey, while the ratio of participants that stated they would firstly apply to emergency department in their country of residence remained at $55.3 \%(\mathrm{p}<0.05)$. While $48.7 \%$ of the participants (n: 73) stated that they found the cleanliness of the emergency department very good in the country where they live, the ratio of participants that state the cleanliness of emergency departments in Turkey as very good remained at $18.7 \%$ (n: 28 ; Table 2).

When participants' views on the healthcare workers in Turkey and in their country of residence were examined, $30 \%$ of the participants (n: 45) stated the attitude of emergency department doctors in Turkey as very good, while $42.7 \%$ (n: 64) stated the attitude

Table 1. Sociodemographic and clinical characteristics.

\begin{tabular}{llcc} 
Variables & Categories & n & \% \\
Gender & Male & 86 & 57.3 \\
& Female & 64 & 42.7 \\
Education status & Literate & 1 & 0.7 \\
& Primary School & 39 & 26 \\
& High School & 70 & 46.7 \\
& University & 40 & 26.7 \\
\hline Country of residence & Germany & 74 & 49.3 \\
& The USA & 1 & 0.7 \\
& Austria & 23 & 15.3 \\
& Belgium & 11 & 7.3 \\
& Denmark & 3 & 2 \\
& France & 17 & 11.3 \\
& The Netherlands & 17 & 11.3 \\
& The UK & 1 & 0.7 \\
& Spain & 1 & 0.7 \\
& Italy & 2 & 1.3 \\
Living in & City & 122 & 81.3 \\
& Countryside & 28 & 18.7 \\
\hline Way of application to & Ambulance & 29 & 19.3 \\
emergency department & On foot & 74 & 49.3 \\
& Private Vehicle & 47 & 31.3 \\
Complaint & Flu & 14 & 9.3 \\
& Headache & 12 & 8 \\
& Fever & 10 & 6.7 \\
& Diarrhea & 9 & 6 \\
& Nausea, vomiting & 7 & 4.7 \\
\hline
\end{tabular}


Table 2. Participants' view about emergency departments

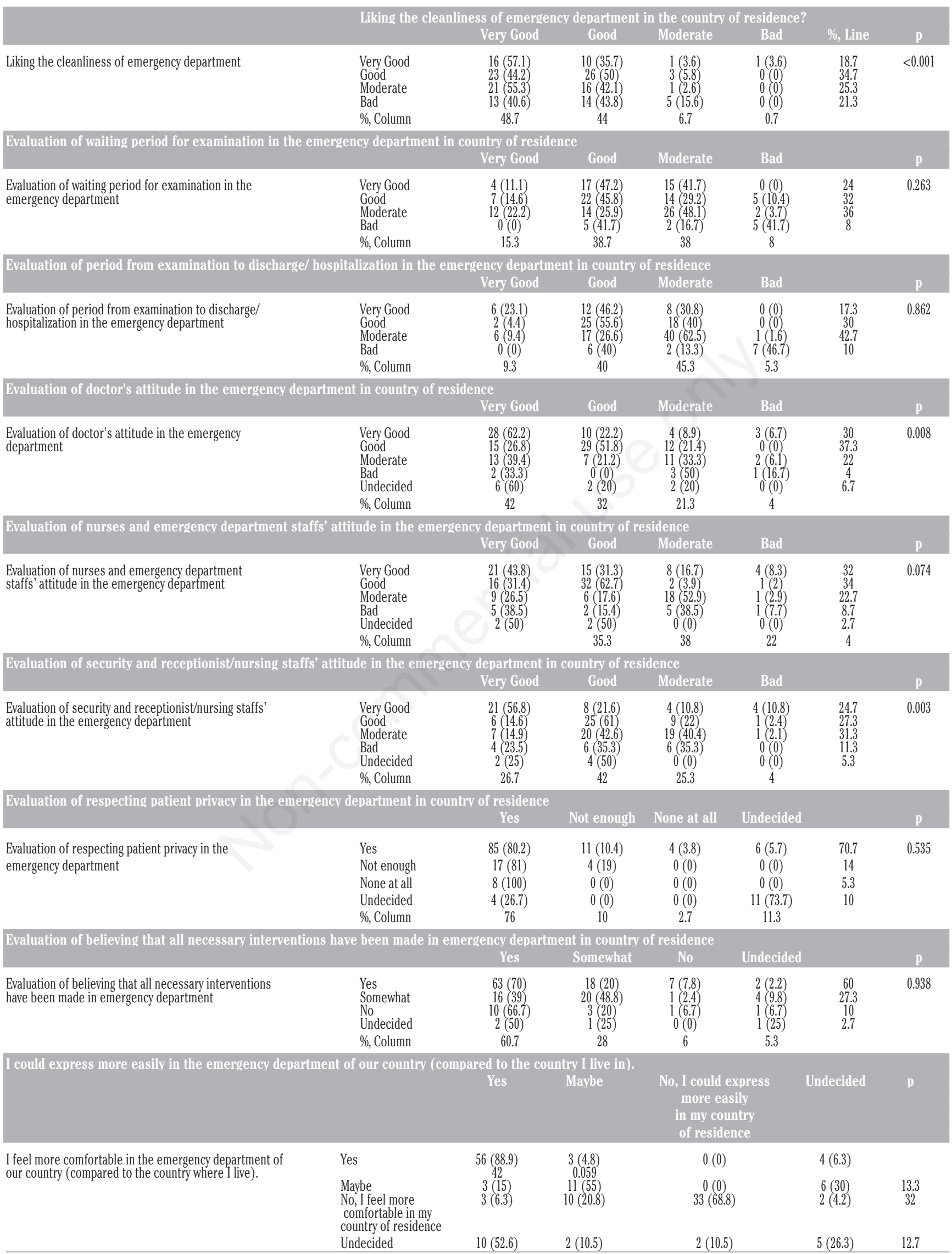


of emergency department doctors in their country of residence as very good $(p<0.05)$. In a similar manner, $32 \%$ of the participants who filled the questionnaire (n: 48) stated the attitude of nurses and healthcare staff in Turkey towards them as very good, 35.3\% (n: 53) stated the attitude of nurses and healthcare staff in their country of residence towards them as very good ( $p>0.005)$. On the other hand, when their views on security and receptionist/nursing staff were examined, $11.3 \%$ of the participants (n: 17) stated the attitude of said staff towards patients in Turkey as very bad, while $4 \%$ of the participants (n: 6) stated the attitude of said staff in their country of residence towards them as very bad (Table 2).

There was no significant difference when the participants view on period from examination to discharge/admission, respect for patient privacy, trust that all necessary interventions were made in the emergency department, waiting time for examination in emergency department in Turkey and in their country of residence were examined $(\mathrm{p}>0.05)$. Also, when asked whether the service received in the emergency department in our country made you proud, $42.7 \%$ of the participants said yes and $24 \%$ answered no. While $42 \%$ of the participants stated that they felt more comfortable in emergency department of our country (compared to the country they live in), $32 \%$ of stated that they felt more comfortable in the emergency department of the country of residence. $48 \%$ of the participants stated that they could express themselves more easily in the emergency department of our country (compared to the country they live in), $23.3 \%$ of them stated that they could express themselves more easily in the emergency department of their country of residence (Table 2).

Two-dimensional graphics were obtained from the variables with significant differences in group comparisons and sociodemographic and clinical variables to better analyze the patients' level of satisfaction from emergency departments in Turkey and their country of residence.

According to these graphs, we found that the group of participants who stated that they would firstly apply to emergency department in Turkey in case of a health problem, consisted mostly males, residing in Germany, between the ages of 35-44 and living in the countryside or the city; while the group of participants who stated that they would firstly apply to emergency departments in their country of residence consisted mostly literate and high school graduates, residing in Germany and France and between the ages of 55-64 (Figure 2). In addition to this, the group of participants that stated the cleanliness of the emergency department in Turkey as very good consisted mostly males, from the age groups between 18-24 and 25-34, junior high school or high school graduates; while the group of participants that stated the cleanliness of the emergency department in their country of residence as very good mostly consisted individuals who reside in Germany or France, between the ages of 45-54 and 55-64, primary school graduate, living in the city and apply to the emergency department as outpatient (Figure 3).

The participants who described the attitude of security and receptionist/nursing staff working in emergency department in Turkey towards patients as very bad were mostly females between the ages of 18-24, university graduate, residing in Germany and living in city; while the participants who described the attitude of the said staff in their country of residence as very bad were only participants from Austria (Figure 4).

The group of participants that stated the attitude of emergency department doctors in Turkey as very good, mostly consisted individuals between the ages of 55-64, residing in Austria and living in countryside; while the group of participants that stated the attitude of emergency department doctors in their country of residence as

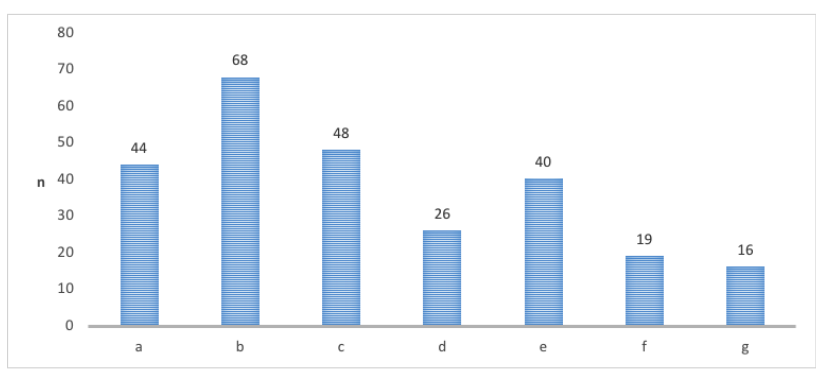

a: I am satisfied with previous care; b: Quick service in emergency department

c: I trust healthcare workers; d: I like the hospital facilities

e: I don't know of any other healthcare service to go; f: I'm not sure where to go

g: I am not satisfied with other health services to apply

Figure 1. Reasons to prefer the emergency service.

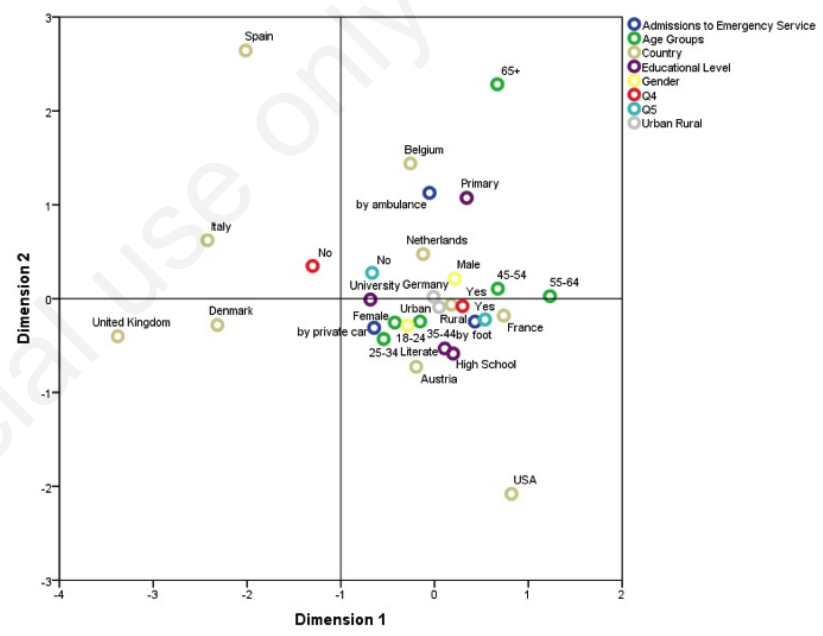

Figure 2. Two-dimensional graph showing the relationship between emergency admission priority (Questions 4 and 5) and clinical and sociodemographic characteristics.

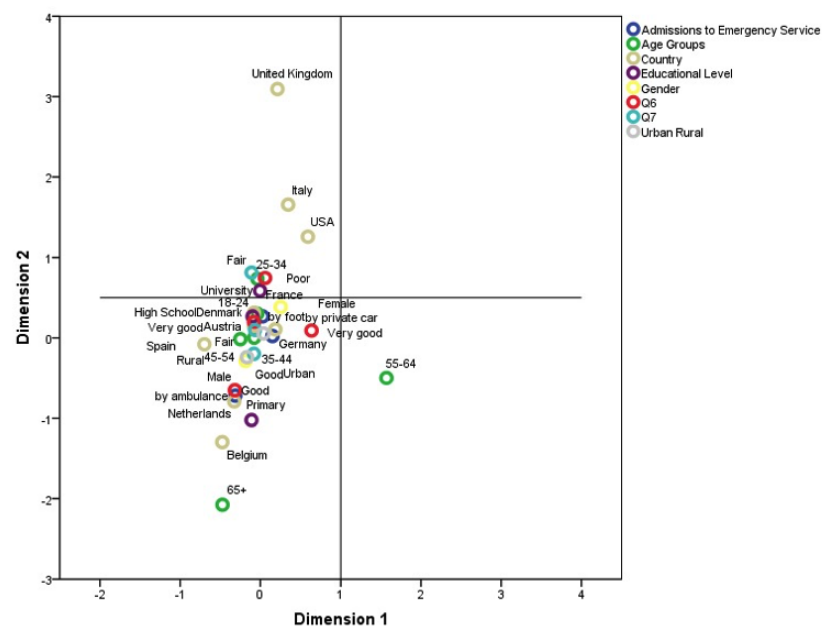

Figure 3. Two-dimensional graph showing the relationship between the state of cleanliness (Questions 6 and 7) in the emergency department and clinical and sociodemographic characteristics. 
very good consisted mostly males, between the ages of 45-54, high school graduate, living in countryside and that apply to emergency department via ambulance (Figure 5).

\section{Discussion}

The use and delivery of health services are among the most important indicators in evaluating the socio-economic development levels of countries. ${ }^{6}$ One of the important criteria for the evaluation of health services is patient satisfaction. In our country, especially in recent years, the importance of emergency health services among healthcare services has been increasing.

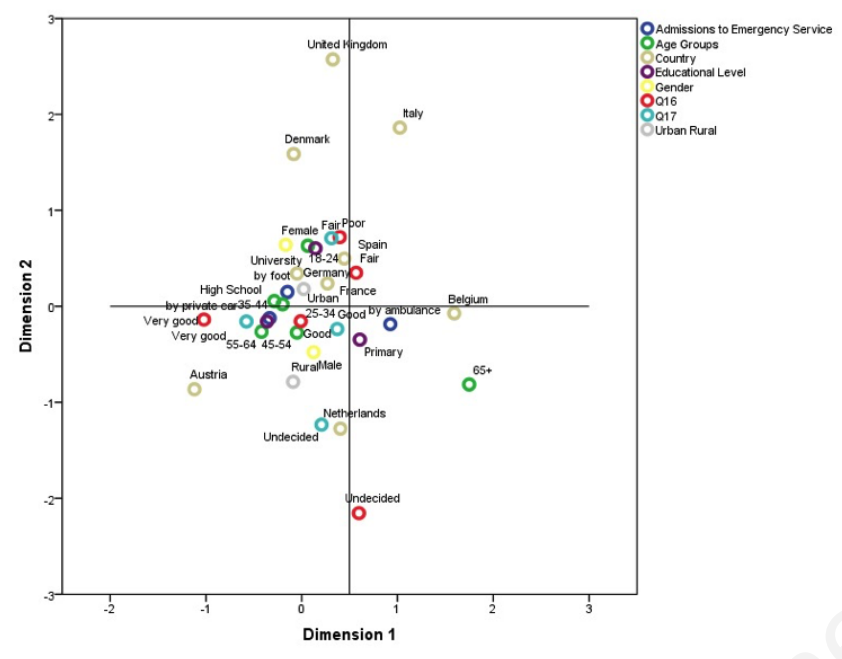

Figure 4. Two-dimensional graph showing the relationship between the attitudes of the security and receptionist/nursing staff in the emergency department (Questions 16 and 17) and clinical and sociodemographic characteristics

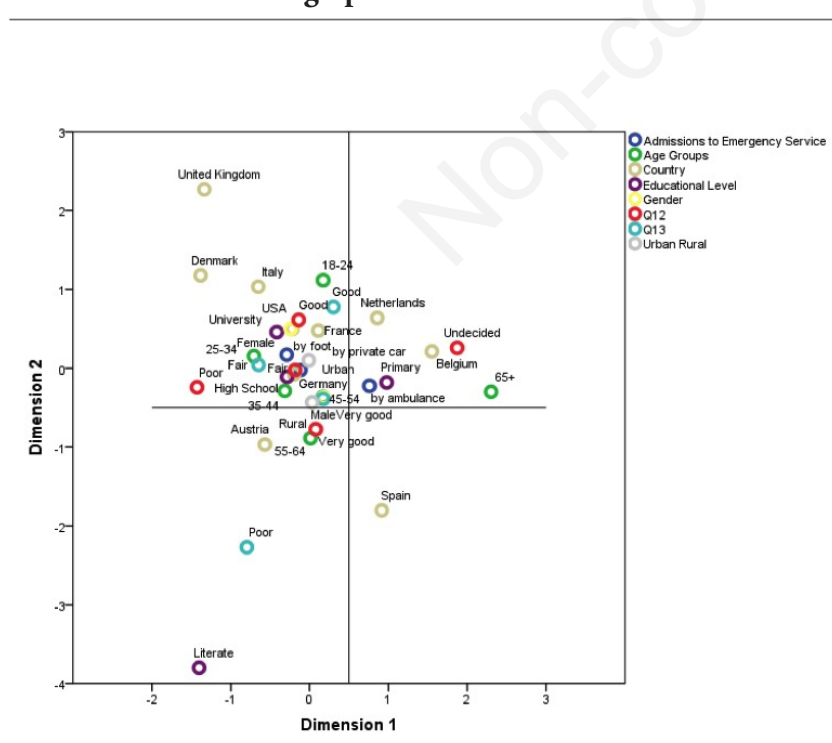

Figure 5. Two-dimensional graph showing the relationship between the attitudes of doctors working in the emergency department (Questions 12 and 13) and clinical and sociodemographic characteristics
The patient's discharge from emergency department in a satisfied manner increases the compliance with the recommended treatment and results in the patient's preference of the same hospital for future healthcare demands. ${ }^{7}$

In a study of Akpınar and Uzel Taş, the reasons for preferring the emergency department were found $21.1 \%$ satisfaction with previous services, $18.9 \%$ proximity to home or work and $15.6 \%$ trust in healthcare workers. ${ }^{7}$ When the reasons for expatriates to prefer the emergency department are examined in our study, it was found that quick healthcare services in emergency department in $26 \%$, trust in emergency staff in $18.4 \%$ and satisfaction with previous services in $16.9 \%$.

In our study, expatriates' average monthly number of applications to emergency department was 1.85 in Turkey and 1.25 in their country of residence. The ratio of the participants that stated they would firstly apply to emergency department in Turkey in case of a health problem was found as $81.3 \%$, while the ratio of participants that stated they would firstly apply to emergency department in their country of residence was $55.3 \%$. These two signs shows that expatriates prefer the emergency department more frequently in Turkey. This situation may be due to both the satisfaction of expatriates with the service they receive from the emergency department in Turkey and the ease of access to emergency departments in Turkey.

There is a serious relationship between patient satisfaction in the emergency department and the quality of the personnel working in the emergency department. In some studies, it has been emphasized that the most important factor affecting satisfaction is the attitude and behavior of the doctors. ${ }^{4,8,9}$ In our study, the rate of participants that stated the attitude of emergency department doctors as very good was $30 \%$ in Turkey and $42.7 \%$ in their country of residence.

In a study conducted by Kabaroglu et al., many factors were found to play an important role in patient satisfaction and it was stated that the most powerfully influencing factor was nurses' attitude and behavior towards patients. ${ }^{10}$ Similarly, some studies emphasized the importance of nurse behavior and medical care on patient satisfaction. ${ }^{4,11}$ In the study of Akpınar and Uzel Taş, ${ }^{7} 52 \%$ of the patients stated the attitude of the nurses as very good; in our study, the rate of participants who stated attitude of nurses and healthcare staff working in emergency department towards patients as very good was $32 \%$ in Turkey and $35.3 \%$ in their country of residence. In addition to this, effectiveness of attitude and behavior on patient satisfaction is not limited with nurses and doctors but also the behaviors of allied health professionals directly affect patient satisfaction. ${ }^{10}$ In our study, the rates of patients that stated the attitude of security and receptionist/nursing staff working in emergency department as very bad was $11.3 \%$ in Turkey and $4 \%$ in their country of residence.

In some studies, the positive effect of cleanliness in emergency department on patient satisfaction was emphasized. ${ }^{12,13}$ In our study, the ratio of participants stated cleanliness of emergency departments as very good was $18.7 \%$ in Turkey and $48.7 \%$ in their country of residence.

In a study conducted by Alici et al., the most influential factors for higher level of patient satisfaction were evaluated as paying attention to personal privacy and also being polite and respectful for all personnel. ${ }^{14}$ In the study conducted by Topal et al., $84 \%$ of the patients stated that attention was paid to personal privacy in the emergency department. ${ }^{15}$ In our study, $70.7 \%$ of participants stated that attention was paid to personal privacy in Turkey and it was $76 \%$ for their country of residence. 


\section{Conclusions}

As a result, it was found that expatriate patients prefer the emergency department more in our country. Also, it was found that expatriate patients were more satisfied with cleanliness of emergency department, attitudes of doctors, security and receptionist/nursing staff in their country of residence comparing to Turkey. We think that these problems can be solved with in-service trainings and more frequent inspection of emergency department cleaning.

\section{Limitations of the study}

The fact that the study is in a single center and the small sample number of participants can be considered as limitations of the study.

\section{References}

1. Boudreaux ED, Mandry CV, Wood K. Patient satisfaction data as a quality indicator: a tale of two emergency departments. Acad Emerg Med 2003;10:261-8.

2. Ozer A, Çak1l E. The factors affecting patient satisfaction in health services. J Med Res 2007;5:140-3.

3. Oztürk A. A research on numerical determination of Beysehir and its region originated expats living abroad and their contributions to regional economy. J Institute Soc Sci 2019; 42:10412.

4. Gultekin Akkaya E, Bulut M, Akkaya C. The factors affecting the level of patients' satisfaction of the applicants for emergency service. Turk J Emerg Med 2012;12:62-8.

5. Lemeshow S, Hosmer DW, Klar J, Lwanga SK, Organization WH. Adequacy of sample size in health studies: Chichester: Wiley; 1990.
6. Dolek M, Turaba F, Akbınar C, et al. The satisfaction levels of patients staying in Emergency Department of Ege University Medical Faculty Hospital. Turk J Emerg Med 2005;5:122-7.

7. Akpınar Oruç O, Uzel Taş H. Level of satisfaction of patients admitting to emergency room. Kocatepe Med J 2014;15:131-6.

8. Yigit O, Oktay C, Bacakoglu G. Analysis of the patient satisfaction forms about emergency department services at Akdeniz University Hospital. Turk J Emerg Med 2010;10:181-6.

9. Karagun O, Yesilagac H, Gulalp B, Gokel Y. What can we do to improve patient satisfaction in the emergency department? A prospective study in a Turkish university hospital. Adv J Emerg Med 2018;2:e41.

10. Kabaroglu K, Eroglu S. E, Onur O. E, et al. The investigation of factors affecting the patient satisfaction in emergency services. Marmara Med J 2013;26:82-9.

11. Mersinlioglu G, Oztürk H. Levels of emergency patients' satisfaction with nursing services. J Health Nurs Manag 2015;2:70-82.

12. Topacoglu H, Karcioglu O, Ozucelik N, et al. Analysis of factors affecting satisfaction in the emergency department: a survey of 1019 patients. Adv Ther 2004;21:380-8.

13. Natesan P, Hadid D, Harb YA, Hitti E. Comparing patients and families perceptions of satisfaction and predictors of overall satisfaction in the emergency department. PLoS ONE 2019; 14:e0221087.

14. Alıcı B, Uzuntarla Y, Turkugur Y, Guleç M. Evaluation of satisfaction levels of the patients who applied to the emergency room of Gulhane Military Faculty of Medicine Training Hospital. TAF Prev Med Bull 2016;15:121-6.

15. Topal F.E, Senel E, Topal F, Mansuroğlu C. A patients' satisfaction study: Satisfaction levels of the patients admitted to emergency clinic of a state hospital. Cumhuriyet Med J 2013;35:199-205. 